\title{
Frequency of serovars and antimicrobial resistance in Shigella spp. from Brazil
}

\author{
Gisele Peirano+ , Flávia dos Santos Souza, Dalia dos Prazeres Rodrigues, \\ Shigella Study Group
}

Laboratório de Referência Nacional de Cólera e outras Enteroinfecções Bacterianas, Instituto Oswaldo Cruz-Fiocruz, Av. Brasil 4365, 21045-900 Rio de Janeiro, RJ, Brasil

A total of 296 Shigella spp. were received from State Public Health Laboratories, during the period from 1999 to 2004, by National Reference Laboratory for Cholera and Enteric Diseases (NRLCED) - IOC/Fiocruz, Rio de Janeiro, Brazil. The frequency of Shigella spp. was: S. flexneri (52.7\%), S. sonnei (44.2\%), S. boydii (2.3\%), and S. dysenteriae $(0.6 \%)$. The most frequent $\mathrm{S}$. flexneri serovars were $2 a$ and $1 b$. The highest incidence rates of Shigella isolation were observed in the Southeast (39\%) and Northeast (34\%) regions and the lowest rate in the South (3\%) of Brazil. Strains were further analyzed for antimicrobial susceptibility by disk diffusion method as part of a surveillance program on antimicrobial resistance. The highest rates of antimicrobial resistance were to trimethoprimsulfamethozaxole (90\%), tetracycline (88\%), ampicillin (56\%), and chloramphenicol (35\%). The patterns of antimicrobial resistance among Shigella isolates pose a major difficulty in the determination of an appropriate drug for shigellosis treatment. Continuous monitoring of antimicrobial susceptibilities of Shigella spp. through a surveillance system is thus essential for effective therapy and control measures against shigellosis.

Key words: Shigella - serovars - antimicrobial resistance surveillance - Brazil

Shigellosis is endemic throughout the world and it is among the most common causes of bacterial diarrhoeal diseases. It is responsible for approximately 165 million cases annually, of which 163 million are in developing countries and 1.5 million in industrialized ones. It is estimated that 1.1 million people die annually from Shigella infection and nearly 580,000 cases of shigellosis are reported among travelers from industrialized countries. The frequency of S. flexneri, S. sonnei, S. boydii, and S. dysenteriae were $60,15,6 \%$, and $6 \%$ (30\% of S. dysenteriae cases were type 1) in developing countries; and 16, 77, 2, and $1 \%$ in developed ones, respectively. In developing countries, the predominant serotype of $S$. flexneri is $2 \mathrm{a}$, followed by 1b, 3a, 4a, and 6 (Kotloff et al. 1999).

Although epidemic Shiga dysentery is the most serious manifestation of Shigella infection in developing countries, the majority of Shigella infections are due to endemic shigellosis. S. flexneri is the endemic species and is responsible for approximately $10 \%$ of all diarrhoeal

Shigella Study Group: Aldo Proeitti Junior, Public Health Laboratory-PHL/AP, Cecília Camilo, PHL/RR, Lécia Maria SS Cosme PHL/MA, Christine K Fontana PHL/PR, Dauri S Rodrigues PHL/SC, Iracema S Miralles PHL/CE, Valdelúcia O Cavalcante PHL/PE, Maria da Penha AH Souza PHL/ES, Hilda Maria R Huf PHL/BA, Marizoneide Gomes PHL/DF, Marinalva Coelho, Children Reference Hospital-PE, Maria Cristina Lourenço, IPEC-Fiocruz.

Financial support: CNPq (process 142069/2001-9), NRLCED, IOC-Fiocruz

+Corresponding author: peirano@ioc.fiocruz.br

Received 20 September 2005

Accepted 29 March 2006 episodes among children younger than five years. $S$. dysenteriae type 1 causes epidemic and endemic disease, whereas, in developed countries, $S$. sonnei is predominantly involved in common source sporadic outbreaks. $S$. boydii, was first detected in India and up to now has been uncommonly found, excepting in the Indian subcontinent (Niyogi 2005).

Except for $S$. sonnei, each species contains multiple serotypes based on the structure of the $\mathrm{O}$ antigen, and, at least 49 serotypes of Shigella have been recognized, representing subtypes from three of the four groups; of which 15 belong to $S$. flexneri (Simmons \& Romanowska 1987, Bopp et al. 2003).

Besides the self-limiting duration of disease, effective antimicrobial therapy reduces dysentery duration and severity and can also prevent potentially lethal complications. Concomitantly, the excretion of the pathogen in stools is shortened significantly, reducing spread of the infection (Bhattacharya \& Sur 2003). However, Shigella spp. can easily become resistant to antibiotics (WHO 2001).

Indiscriminate use of drugs and horizontal gene transfer has led to Shigella species becoming resistant to commonly used antibiotics. Resistance patterns are influenced by geographic location, year that isolates were obtained, classes of antimicrobial agents, and pressure exerted by antimicrobial use. It was noticed that, over the past decades, Shigella strains have progressively become resistant to most of the widely use antimicrobials, such as ampicillin, chloramphenicol, tetracycline, and trimethoprim-sulfamethoxazole (Lima et al. 1995, Ashkenazi et al. 2003). The antimicrobials that remain effective are ciprofloxacin and other fluoroquinolones, ceftriaxone, and azithromycin (Anonymous 2004). There are also quite striking geographic differences in the corresponding resistance rates. The antimicrobial resistance pattern differs 
between places. This may be due to the occurrence and spread of antimicrobial-resistant clones.

Surveillance programs on antimicrobial resistance not only identify pathogenic bacterial species, by reporting data like serotyping, microorganisms incidence rates, and susceptibility to the antimicrobial agents currently used for treatment, but also contribute to monitoring the intervention strategies used to control their spread (WHO 2001).

Since in Brazil shigellosis is not considered a compulsory notifiable disease, it has been difficult to estimate its incidence rate and respective importance on disseminating antimicrobial resistance.

This study was conducted to evaluate the frequency of species, serovars, and antimicrobial resistance profiles of Shigella spp. received from 1999 to 2004, by Brazilian Shigella Surveillance Program on Antimicrobial Resistance conducted by National Reference Laboratory for Cholera and Enteric Diseases, Fiocruz, Ministry of Health, Brazil.

\section{MATERIALS AND METHODS}

Bacterial isolates - This study included 296 Shigella isolates selected from NRLCED Strain Collection. Such strains were isolated from human fecal samples, from both hospitals and outbreaks, and sent by State Public Health Laboratories to NRLCED for further identification and serotyping.

Selective and differential media were used for isolating Shigella (xylose-lysine-desoxycholate - XLD Agar, Oxoid, UK). Isolates identification was confirmed by standard biochemical laboratory methods (Bopp et al. 2003). Shigella antisera was raised in NRLCED, Fiocruz, and serological identification was performed by slide agglutination with polyvalent somatic $(\mathrm{O})$ antigen grouping sera followed by testing with monovalent antisera for specific serovar.

Strains were also submitted to antimicrobial susceptibility testing as part of a surveillance program on antimicrobial resistance and stored in NRLCED Strain Collection. All isolates were stored on phosphorous nutrient agar glass tubes and kept at room temperature $\left(20-30^{\circ} \mathrm{C}\right)$.

Antimicrobial susceptibility testing - Antimicrobial susceptibility testing was performed in 278 Shigella strains by standard disk diffusion method, following NCCLS guideline. Tests were performed on Mueller Hinton agar plates, using antimicrobial disks (Oxoid): ampicillin (AMP $10 \mu \mathrm{g}$ ), amikacin (AMK $30 \mu \mathrm{g}$ ), cefoxitin (FOX 30 $\mu \mathrm{g})$, ceftriaxone (CRO $30 \mu \mathrm{g})$, cephalothin (CEF $30 \mu \mathrm{g})$, chloramphenicol (CHL $30 \mu \mathrm{mg}$ ), ciprofloxacin (CIP $5 \mu \mathrm{g}$ ), gentamicin (GEN $10 \mu \mathrm{g}$ ), imipenem (IPM $10 \mu \mathrm{g}$ ), nalidixic acid (NAL $30 \mu \mathrm{g}$ ), nitrofurantoin (NIT $300 \mu \mathrm{g}$ ), tetracycline (TET $30 \mu \mathrm{g}$ ), and trimethoprim-sulfamethoxazole (SXT 1,25/23,75 $\mu \mathrm{g}$ ). Standard control strains of Escherichia coli (ATCC 25922), Pseudomonas aeruginosa (ATCC 27852), Enterococcus faecalis (ATCC 29212), and Staphylococcus aureus (ATCC 29213) were used for monitoring the accuracy and precision of the disk diffusion test. The interpretation of zone diameters inhibition was that recommended by NCCLS (2003).

\section{RESULTS}

The serogroups prevalence of the 296 Shigella isolates was as follows: S. flexneri, $n=156(52.7 \%)$, S. sonnei, $n=131(44.2 \%)$, S. boydii, $n=7$ (2.3\%), and S. dysenteriae, $n=2(0.6 \%)$. Table I shows the distribution of Shigella strains according to the year and to the Brazilian region from which they were isolated. It was observed the highest incidence rates of isolation in the Southeast (39\%) and Northeast (34\%) regions, and the lowest rate in the South (3\%) region. It was additionally found that the number of $S$. flexneri was higher than that of S. sonnei isolates (65 and 33, respectively) in the Northeast; and that in the Southeast it was the opposite (74 S. sonnei and 42 S. flexneri).

The most frequent serotypes identified for $S$. flexneri were $2 \mathrm{a}$ and $1 \mathrm{~b}$. Both $S$. boydii and S. dysenteriae showed a very low number of isolates. Table II shows the distribution of Shigella species and serovars.

Overall, the highest rates of antimicrobial resistance among Shigella isolates were to trimethoprim-sulfamethozaxole (90\%), tetracycline (88\%), ampicillin (56\%), and chloramphenicol (35\%). Additionally twelve isolates and four isolates showed intermediate resistance to nalidixic acid and to ciprofloxacin, respectively. None of the isolates was resistant to imipenem (Table III).

S. flexneri and S. sonnei shared a similar antimicrobial resistance profile for most of the antibiotics. Among the 278 Shigella isolates tested, $97.8 \%$ were resistant to both one or more antimicrobial agents, and $91 \%$ to either two or more antimicrobial agents. Antimicrobial resistance profiles to TET and SXT resistance occurred in 30\% of isolates and to AMP, CHL, TET, and SXT in $22 \%$ of isolates (Table IV).

\section{DISCUSSION}

Shigellosis is becoming an increasingly significant public health problem due to development of multiple antimicrobial resistance, frequently resulting in treatment failure, leading in turn to health complications and deaths (Sur et al. 2004).

In the Brazilian Shigella Surveillance Program, $S$. flexneri was the predominant isolated Shigella serogroup $(\approx 53 \%$ ) during the studied period, followed by S. sonnei $(\approx 44 \%)$. This is in contrast with studies from other places in Brazil, which detected S. sonnei as the most frequent serogroups: Ribeirão Preto-SP (Medeiros et al. 2001), and Salvador-BA (Diniz-Santos et al. 2005). However, our finding is consistent with other reports from Northeastern Brazil (Lima et al. 1995), Porto Alegre-RS (Santos et al. 1997), and São José do Rio Preto-SP (Almeida et al. 1998), and those from other Latin America developing countries such as Argentina (Merino et al. 2004), Peru (Jones et al. 2004), and Chile (Fulla et al. 2005).

We also noticed some differences in the Shigella geographical isolation incidence among Brazilian regions. S. flexneri was observed to have higher isolation incidence in the Northeast, and S. sonnei were more frequently isolated in the Southeast. These two Brazilian regions are social and economically quite different, the Southeast being more likely to have developed cities. This may be 
Regional distribution of Shigella species in Brazil (1999-2004)

\begin{tabular}{|c|c|c|c|c|c|}
\hline & Year & S. flexneri & S. sonnei & S. boydii & S. dysenteriae \\
\hline $\begin{array}{l}\text { Southeast } \\
(n=118)\end{array}$ & $\begin{array}{l}1999 \\
2000 \\
2001 \\
2002 \\
2003 \\
2004\end{array}$ & $\begin{array}{r}2 \\
4 \\
18 \\
4 \\
4 \\
10\end{array}$ & $\begin{array}{r}7 \\
6 \\
32 \\
17 \\
9 \\
3\end{array}$ & 1 & 1 \\
\hline $\begin{array}{l}\text { Northeast } \\
(n=101)\end{array}$ & $\begin{array}{l}1999 \\
2000 \\
2001 \\
2002 \\
2003 \\
2004\end{array}$ & $\begin{array}{r}8 \\
8 \\
9 \\
20 \\
1 \\
19\end{array}$ & $\begin{array}{l}11 \\
5 \\
7 \\
1 \\
9\end{array}$ & $\begin{array}{l}1 \\
2\end{array}$ & \\
\hline $\begin{array}{l}\text { North } \\
(n=38)\end{array}$ & $\begin{array}{l}1999 \\
2000 \\
2001 \\
2002 \\
2003 \\
2004\end{array}$ & $\begin{array}{l}6 \\
6 \\
9 \\
6 \\
2\end{array}$ & $\begin{array}{l}1 \\
2\end{array}$ & 2 & \\
\hline $\begin{array}{l}\text { Middle-West } \\
(n=30)\end{array}$ & $\begin{array}{l}1999 \\
2000 \\
2001 \\
2002 \\
2003 \\
2004\end{array}$ & $\begin{array}{l}5 \\
3 \\
8 \\
4\end{array}$ & $\begin{array}{l}2 \\
3\end{array}$ & 1 & 1 \\
\hline $\begin{array}{l}\text { South } \\
(n=9)\end{array}$ & $\begin{array}{l}1999 \\
2000 \\
2001 \\
2002 \\
2003 \\
2004\end{array}$ & & $\begin{array}{l}8 \\
1\end{array}$ & & \\
\hline Total & & 156 & 131 & 7 & 2 \\
\hline
\end{tabular}

TABLE II

Distribution of Shigella spp. serotypes occurring in Brazil

\begin{tabular}{l} 
Shigella spp. \\
\hline $\begin{array}{l}\text { S. dysenteriae } \\
\text { serotype } 2\end{array}$ \\
S. flexneri \\
serotype $1 \mathrm{a}$ \\
serotype $1 \mathrm{~b}$ \\
serotype $2 \mathrm{a}$ \\
serotype $2 \mathrm{~b}$ \\
serotype $3 \mathrm{a}$ \\
serotype $4 \mathrm{a}$ \\
serotype $4 \mathrm{c}$ \\
serotype 6
\end{tabular}

Not determined

S. boydii serotype 4

S. sonnei serotype I

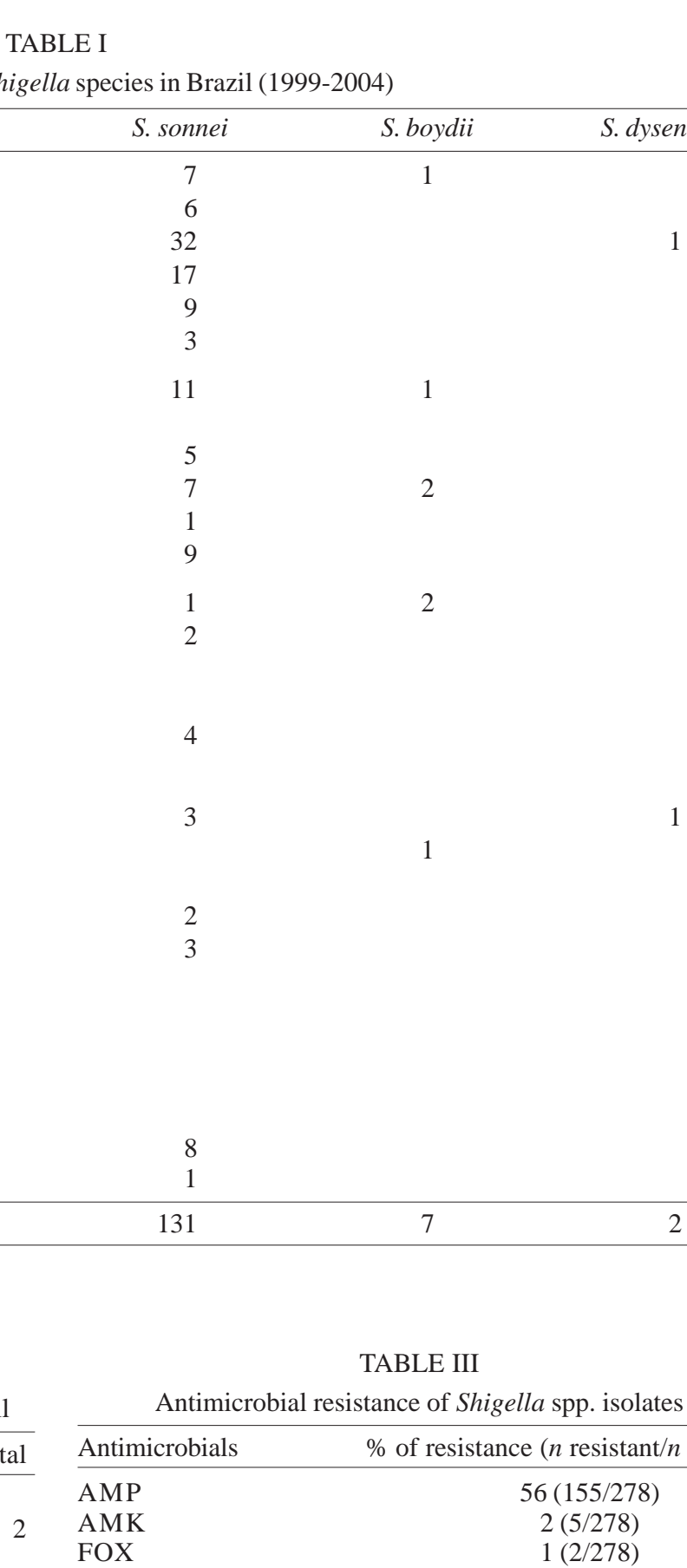

Total

2

$2(5 / 278)$

$1(2 / 278)$

$1(2 / 278)$

$18(55 / 278)$

$35(97 / 278)$

$2\left(4^{a} / 278\right)$

$5(13 / 278)$

$0(0 / 278)$

$5\left(12^{a} / 278\right)$

$1(1 / 278)$

$88(244 / 278)$

$90(250 / 278)$ 
TABLE IV

Antimicrobial resistance profiles of Shigella in Brazil (1999-2004)

\begin{tabular}{|c|c|c|c|c|c|c|}
\hline Antimicrobial resistance profile & 1999 & 2000 & 2001 & 2002 & 2003 & 2004 \\
\hline AMP & & & 1 & & 5 & \\
\hline GEN & & & & 1 & & \\
\hline SXT & 1 & & 1 & & 3 & \\
\hline TET & 1 & & 4 & 1 & 1 & \\
\hline AMP, CHL & & 1 & & & & \\
\hline AMP, SXT & 7 & & 2 & & 1 & 1 \\
\hline AMP, TET & 2 & & & & 1 & \\
\hline CEF, GEN & & & & 1 & & \\
\hline CEF, TET & & & & 1 & & \\
\hline CRO, SXT & & 1 & & & & \\
\hline TET, SXT & 23 & 11 & 24 & 7 & 9 & 9 \\
\hline AMP, CEF, SXT & & & & & 2 & \\
\hline AMP, CHL, SXT & 3 & 1 & 1 & & & \\
\hline AMP, CHL, TET & 2 & 1 & 1 & 1 & & 2 \\
\hline AMP, TET, SXT & 2 & 2 & 7 & 2 & 3 & 3 \\
\hline AMK, TET, SXT & & & & & 1 & \\
\hline CEF, TET, GEN & & & & 1 & & \\
\hline CEF, TET, SXT & & & 1 & 5 & 1 & \\
\hline AMP, AMK, CEF, SXT & & & & & & 1 \\
\hline AMP, CHL, TET, SXT & 5 & 10 & 15 & 10 & 3 & 19 \\
\hline AMP, CEF, TET, SXT & & & 2 & 15 & & \\
\hline CEF, GEN, TET, SXT & & & & 5 & & \\
\hline CEF, CHL, TET, SXT & & & & & & 1 \\
\hline CEF, NIT, TET, SXT & & & & 1 & & \\
\hline FOX, GEN, TET, SXT & & & & & 1 & \\
\hline AMP, CEF, CHL, TET, SXT & & & & 12 & & 2 \\
\hline AMP, CHL, GEN, TET, SXT & & & 1 & & & \\
\hline AMP, AMK, CHL, TET, SXT & & & & & & 2 \\
\hline CEF, CHL, GEN, TET, SXT & & & & 1 & & \\
\hline AMP, CEF, CHL, FOX, TET, SXT & & & & & 1 & \\
\hline AMP, AMK, CHL, GEN, TET, SXT & & & & & 1 & \\
\hline AMP, AMK, CEF, CRO, TET, SXT & & & & & & 1 \\
\hline AMP, AMK, CEF, CHL, GEN, TET, SXT & & & 1 & & & \\
\hline
\end{tabular}

AMP: ampicillin; AMK: amikacin; FOX: cefoxitin; CRO: ceftriaxone; CEF: cephalothin; CHL: chloramphenicol; GEN: gentamicin; NIT: nitrofurantoin; TET: tetracycline; SXT: trimethoprim/sulfamethoxazole.

due to the modern lifestyle of developed cities, where the main ways of contracting shigellosis are by eating and/or drinking fecal contaminated food/water, and by personto-person contact. The pathogens can be also transferred by flies, fingers, feces, food, and fomites. High-risk groups include children in day-care centers, homosexual men, people in custodial institutions, migrant workers, and travelers.

Our data showed very low occurrence of $S$. boydii and $S$. dysenteriae. Infections by $S$. dysenteriae usually occur in less developed countries, often reaching epidemic levels, with periodic outbreaks (Niyogi 2005).

Serotypes $2 \mathrm{a}$ and $1 \mathrm{~b}$ were the most frequent serotypes of $S$. flexneri in this study, accounting for 59 and $21 \%$, respectively, of the $S$. flexneri serotyped isolates. These are the most common serotypes occurring in developing countries (Kotloff et al. 1999, Souza 2001).

Appropriate antibiotic treatment of shigellosis depends on identifying Shigella resistance patterns that are circulating locally. These imply in local surveillance of antimicrobial resistance and its implication in empirical therapy (Ashkenazi 2004).

According to analyzed isolates, S. flexneri antimicrobial resistance patterns were mainly detected to ampicillin, chloramphenicol, tetracycline, and trimethoprimsulfamethoxazole. S. sonnei presented a similar resistance profile, except for chlorampenicol, but with increasing resistance to cephalotin. Overall, it could be observed that such main resistance antimicrobial pattern (ampicillin, chloramphenicol, tetracycline, and trimethoprimsulfamethoxazole) continues to be prevalent among Shigella isolates from Brazil (Lima et al. 1995, Rodrigues 2000). Also, in a recent study (Diniz-Santos et al. 2005) Shigella species presented a very high resistance rate to trimethoprim-sulfamethoxazole $(90.1 \%)$, ampicillin (22\%) alone or in combination with sulbactam, and also to piperacillin.

Antimicrobial agents as effective options for shigellosis treatment are becoming limited due to globally emerging drug resistance. Multiple resistant strains have oc- 
curred in Europe (Maraki et al. 1998), Africa (Egah et al. 2003), Asia (Lee et al. 2001), and South America (Fulla et al. 2005). In the United States, the most common resistance rates among 620 Shigella isolates (86\% of which were $S$. sonnei) were to ampicillin (77\%), streptomycin $(54 \%)$, trimethoprim-sulfamethoxazole (37\%), sulfamethoxazole (32\%), and tetracycline (31\%) (CDC 2004). A similar resistance pattern was reported from England and Wales (Cheasty et al. 1998). Data from developing countries, such as Chile, indicate that most Shigella spp. are resistant to ampicillin (82\%), cotrimoxazole (65\%), tetracycline (53\%), and chloramphenicol (49\%) (Fulla et al. 2005). Reports from Bangladesh, where shigellosis is highly endemic, show a similar resistance pattern (Sur et al. 2003) compared to the ones in Latin America. Outbreaks caused by multiresistant $S$. dysenteriae type 1, including strains resistant to nalidixic acid, has also been reported. (Sarkar et al. 2003).

Thus, neither ampicillin, chloramphenicol, tetracyclines nor trimethoprim-sulfamethoxazole should be considered appropriate empiric therapy for shigellosis any longer. Nowadays, recommended therapy for people infected with Shigella includes fluoroquinolones (Bhattacharya \& Sur 2003, Khan et al. 2004, Anonymous 2004), azithromycin (Basualdo \& Ardo 2003), and thirdgeneration cephalosporins (Niyogi et al. 2001).

However, it has been observed that $S$. sonnei have shown readily acquisition of resistance to ampicillin and cephalosporins through conjugative resistance-plasmids carrying resistance cassettes to beta-lactamases (Radice et al. 2001) and, in both S. sonnei and S. flexneri, chromosomal mutations that confer quinolones resistance (Jeong et al. 2003).

Continuous monitoring of antimicrobial susceptibilities of Shigella spp. through a surveillance system is thus essential for effective therapy and control measures against shigellosis. It is also of concern the use of nalidixic acid as a first step screening test to detect mutations causing fluoroquinolone resistance.

\section{ACKNOWLEDGEMENTS}

To Mr Evaldo Soares for technical assistance.

\section{REFERENCES}

Almeida MTG, Silva RM, Donaire LM, Moreira LE, Martinez MB 1998. Enteropathogens associated with acute diarrheal disease in children. J Pediatr 74: 291-298.

Anonymous 2004. Antibiotics in the management of shigellosis. Wkly Epidemiol Rec 79: 355-356.

Ashkenazi S 2004. Shigella infection in children: new insights. Sem Pediatr Infect Dis 15: 246-252.

Ashkenazi S, Levy I, Kazaronovski V, Samra Z 2003. Growing antimicrobial resistance of Shigella isolates. J Antimicrob Chemother 51: 427-429.

Basualdo W, Arbo A 2003. Randomized comparison of azithromycin versus cefixime for treatment of shigellosis in children. Pediatr Infect Dis J 22: 374-377.

Bhattacharya SK, Sur D 2003. An evaluation of current shigellosis treatment. Expert Opin Pharmacother 4: 1315-1320.
Bopp CA, Brenner FW, Fields PI, Wells JG, Strockbine NA 2003. Escherichia, Shigella, and Salmonella. In PR Murray, EJ Baron, JH Jorgensen, MA Pfaller, RH Yolken (eds), Manual of Clinical Microbiology, 7th ed., American Society of Microbiology, Washington DC, p. 654-671.

CDC-Centers for Disease Control and Prevention 2004. National Antimicrobial Resistance Monitoring System for Enteric Bacteria (NARMS): 2002 Human Isolates Final Report. Atlanta, Georgia: US Department of Health and Human Services, CDC. Available at http://www.cdc.gov/ narms/annual/2002/2002ANNUALREPORTFINAL.pdf.

Cheasty T, Skinner JA, Rowe B, Threlfall EJ 1998. Increasing incidence of antibiotic resistance in shigellas from humans in England and Wales: recommendations for therapy. Microb Drug Resist 4: 57-60.

Diniz-Santos DR, Santana JS, Barretto JR, Andrade MGM, Silva LR 2005. Epidemiological and microbiological aspects of acute bacterial diarrhea in children from Salvador, Bahia, Brazil. Braz J Infect Dis 9: 77-83.

Egah DZ, Banwat EB, Audu ES, Allanana JA, Danung ML, Damen JG, Badung BP 2003. Multiple drug resistant strains of Shigella isolated in Jos, central Nigeria. Niger Postgrad Med J 10: 154-156.

Fulla N, Prado V, Duran C, Lagos R, Levine MM 2005. Surveillance for antimicrobial resistance profiles among Shigella species isolated from a semirural community in the northern administrative area of Santiago, Chile. Am J Trop Med Hyg 72: 851-854.

Jeong YS, Lee JC, Kang HY, Yu HS, Lee EY, Choi CH, Tae SH, Lee YC, Cho DT, Seol SY 2003. Epidemiology of nalidixic acid resistance and TEM-1 and TEM-52-mediated ampicillin resistance of Shigella sonnei isolates obtained in Korea between 1980 and 2000. Antimicrob Agents Chemother 47: 3719-3723.

Jones FR, Sanchez JL, Meza R, Batsel TM, Burga R, Canal E, Block K, Perez J, Bautista CT, Escobedo J, Walz SE 2004. Short report: High incidence of shigellosis among Peruvian soldiers deployed in the Amazon River basin. Am J Trop Med Hyg 70: 663-665.

Khan AI, Huq S, Malek MA, Hossain MI, Talukder KA, Faruque AS, Salam MA, Sack DA 2004. Shigella serotypes among hospitalized patients in urban Bangladesh and their antimicrobial resistance. Epidemiol Infect 132: 773-777.

Kotloff KL, Winickoff JP, Ivanoff B, Clemens JD, Swerdlow DL, Sansonetti PJ, Adak GK, Levine MM 1999. Global burden of Shigella infections: implications for vaccine development and implementation of control strategies. Bull WHO 77: 651-666.

Lee JC, Oh JY, Kim KS, Jeong YW, Cho JW, Park JC, Seol SY, Cho DT 2001. Antimicrobial resistance of Shigella sonnei in Korea during the last two decades. APMIS 109: 228-234.

Lima AAM, Lima NL, Pinho MCN, Barros Junior EA, Teixeira MJ, Martins MCV, Guerrant RL 1995. High frequency of strains multiply resistant to ampicillin, trimethoprimsulfamethoxazole, streptomycin, chloramphenicol, and tetracycline isolated from patients with shigellosis in northeastern Brazil during the period 1988 to 1993. Antimicrob Agents Chemother 39: 256-259.

Maraki S, Georgiladakis A, Christidou A, Scoulica E, Tselentis Y 1998. Antimicrobial susceptibilities and beta-lactamase 
production of Shigella isolates in Crete, Greece, during the period 1991-1995. APMIS 106: 879-883.

Medeiros MIC, Neme SM, Silva P, Capuano DM, Errera MC, Fernandes SA, Valle GR, Ávila FA 2001. Etiology of acute diarrhea among children in Ribeirão Preto-SP, Brazil. Rev Inst Med Trop São Paulo 43: 21-24.

Merino LA, Hrenuk GE, Ronconi MC, Alonso JM 2004. Antibiotic resistance and molecular epidemiology of Shigella spp. in northeastern Argentina. Rev Panam Salud Publica 15: 219-224.

NCCLS-National Committee for Clinical Laboratory Standards 2003. Performance Standard for Antimicrobial Disk Susceptibility Tests. Approved Standard, 8th ed., Wayne, PA, NCCLS document M2-A8.

Niyogi SK 2005. Shigellosis. J Microbiol 43: 133-143.

Niyogi SK, Mitra U, Dutta P 2001. Changing pattern of serotypes, antimicrobial susceptibilities of Shigella species isolated from children in Calcutta. Jpn J Infect Dis 54: 121122.

Radice M, González C, Power P, Vidal MC, Gutkind G 2001. Third-generation cephalosporin resistance in Shigella sonnei, Argentina. Emerg Infect Dis 7: 1-2.

Rodrigues DP 2000. Surveillance of antimicrobial resistance in bacterial enteropathogens isolated in Brazil. In R SalvatierraGonzales, Y Benguigui (eds), Antimicrobial Resistance in the Americas: Magnitude and Containment of the Problem. $\mathrm{PAHO} / \mathrm{HGP} / \mathrm{HCT} / 163 / 2000$.

Santos BA, Pires AA, Souza ARM, Vives C, Barcellos S, Bo DJD 1997. Study of in vitro antimicrobial resistance of positive coprocultures to Shigella sp. J Pediatr 73: 395400 .

Sarkar K, Ghosh S, Niyogi SK, Bhattacharya SK 2003. Shigella dysenteriae type 1 with reduced susceptibility to fluoroquinolones. Lancet 361: 785 .

Simmons DA, Romanowska E 1987. Structure and biology of Shigella flexneri $\mathrm{O}$ antigens. J Med Microbiol Rev 23: 289302.

Souza FS 2001. Study of Characteristics Phenotypics and Genotypics in Shigella flexneri, Fundação Oswaldo Cruz, Rio de Janeiro, 104 pp.

Sur D, Niyogi SK, Sur S, Datta KK, Takeda Y, Nair GB, Bhattacharya SK 2003. Multidrug-resistant Shigella dysenteriae type 1: forerunners of a new epidemic strain in Eastern India? Emerg Infect Dis 9: 404-405.

Sur D, Ramamurthy T, Deen J, Bhattacharya SK 2004. Shigellosis: challenges and management issues. Indian J Med Res 120: 454-462.

WHO-World Health Organization 2001. Antimicrobial resistance in shigellosis, cholera, and campylobacteriosis.WHO/ CDS/CSR/DRS/2001.8, Geneva. 